\title{
Programa de saúde da família e agentes comunitários: demandas para além da saúde básica*
}

\author{
'Programa de saúde da família' (family's health program) \\ and community agent: demands for more than basic health
}

\author{
Ana Paula Serrata Malfitano(1), Roseli Esquerdo Lopes ${ }^{(2)}$
}

\begin{abstract}
MALFITANO, A. P. S.; LOPES, R. E. Programa de saúde da família e agentes comunitários: demandas para além da saúde básica. Rev. Ter. Ocup. Univ. São Paulo, v. 14, n. 3, p. 110-7, set./ dez. 2003.

RESUMO: O presente trabalho problematiza, a partir de uma perspectiva sócio-histórica das políticas de saúde no Brasil, o Programa de Saúde da Família (PSF). Através do estudo das políticas de saúde observa-se a inclusão/exclusão de grupos populacionais e/ou problemáticas não tradicionalmente acolhidos pelos serviços de saúde, e padrões diferenciados de proteção social que intervêm diretamente na vida da população assistida. O objetivo deste trabalho é discutir a inclusão e a exclusão de demandas daqueles grupos populacionais através da ação do Programa de Saúde da Família, enfocando a ação dos agentes comunitários. O estudo de campo se deu na região do Belém, na cidade de São Paulo, onde foram entrevistados os membros da equipe do PSF, bem como acompanhadas as ações de cinco agentes comunitários de saúde, que atuam em uma área empobrecida e marcada pela presença de cortiços, localizados no centro expandido da capital paulista. Essa região se caracteriza por um contexto de participação ativa no movimento social organizado, especialmente no movimento popular por moradia, e três dos seus agentes comunitários são membros deste movimento, sendo dois deles lideranças em suas comunidades. A partir da análise da ação desses agentes comunitários e de sua compreensão sobre o programa por cuja execução na comunidade são responsáveis, são questionadas as ações tradicionalmente entendidas como de 'saúde básica', bem como suas relações com as 'ações básicas de saúde'.
\end{abstract}

DESCRITORES: Saúde da família. Planos e programas de saúde. Política de saúde. Redes comunitárias.

\footnotetext{
" Este trabalho é parte da pesquisa "Ações Básicas de Saúde e a Construção do SUS: Cidadania, Direitos e Políticas Públicas", coordenada pela Profa. Dra. Roseli Esquerdo Lopes, e traz, parcialmente, dados de um dos seus subprojetos: "Políticas Públicas e Movimentos Sociais: Atenção à Infância e o Programa de Saúde da Família”, que integra o trabalho de mestrado em andamento de Ana Paula Serrata Malfitano.

(1) Mestranda do Laboratório de Política Pública e Planejamento da Faculdade de Educação da Universidade Estadual de Campinas - UNICAMP.

(2) Professora Doutora da Faculdade de Educação da Universidade Estadual de Campinas - UNICAMP.

Endereço para correspondência: Departamento de Fisioterapia, Fonoaudiologia e Terapia Ocupacional da Faculdade de Medicina da Universidade de São Paulo. Rua Cipotânea, 51. 05360-000. São Paulo, SP.
} 


\section{SAÚDE ENQUANTO DIREITO}

$\mathrm{O}$ acesso à saúde no Brasil percorre uma trajetória que vai da filantropia ao direito, configurando-se a primeira como traço determinante para a maioria absoluta dos brasileiros e estando ainda bastante presente em muitas ações.

Neste percurso, vários fatos contribuíram para a constituição do imaginário brasileiro no que se refere ao conceito de saúde e de assistência à saúde. Um ponto de extrema influência diz respeito às Caixas de Aposentadorias e Pensões (CAPs) - mais tarde os Institutos de Aposentadorias e Pensões (IAPs) -, que consistiam em um seguro para trabalhadores do setor privado, garantindo pensões, aposentadorias e assistência médica a filiados e dependentes, financiadas através de contribuição compulsória estipulada contratualmente (LOPES, 2001; MERHY, 1997).

Nesse contexto, a noção de assistência médica para o trabalhador é tida naquele imaginário como um direito derivado do contrato de trabalho, uma contrapartida à contribuição de parte do salário, em oposição à assistência médica de natureza pública e filantrópica, a ser oferecida à população carente, fora do mercado formal de trabalho (LOPES, 2001).

\begin{abstract}
A saúde não é, portanto, um direito de cidadania a ser usufruído por todo brasileiro e garantido pelo Estado; não é sequer um direito do trabalhador - o que se criou foi um conceito muito mais restritivo, o da assistência médica, vista como um retorno devido, no caso dos inseridos no mercado formal, ou uma dádiva piedosa, caso contrário. A assistência médica - e a garantia da saúde em geral - eram vistos como pertinentes à esfera privada e não à pública (LOPES, 2001, p.24-5).
\end{abstract}

A década de 70 viveu a hegemonia do modelo médico-assistencial privatista (MENDES, 1993), que se constituiu a partir de ações de um subsistema estatal simplificado e de ações majoritárias de um subsistema privado contratado e conveniado, com financiamento público, e privado de atenção médica supletiva.

Este modelo esgota-se no final da década de 70, segundo Mendes (1993), tendo como pano de fundo a crise fiscal do Estado, com fortes repercussões na Previdência Social e, como tema central, a não resolutividade do modelo.

A partir dos anos 80 inicia-se o processo de redemocratização do país, com a reconquista de alguma cidadania política. É nesta época que ganha grande impulso a discussão da reforma sanitária brasileira, dentro do chamado 'processo de abertura democrática' e sob pressão dos movimentos populares e da sociedade civil (LOPES, 2001).

Os novos horizontes trouxeram à cena política novos atores e diferenciados projetos. A par do extraordinário fortalecimento dos movimentos sociais, alguns já em curso desde a década de 70 , revigorou-se também o sindicalismo: ambos puderam afinal eclodir publicamente, após décadas de repressão. A crise e os sucessivos escândalos na Previdência Social - foco de fantástica corrupção, clientelismo político, desvio de recursos públicos para outras finalidades e má administração - e o aumento do contingente de excluídos que só tinham acesso a serviços de saúde de segunda categoria ou à filantropia, eram razões mais que suficientes para que as forças sociais que discutiam a questão saúde se estruturassem para debatê-la em processo que, a partir de conferências municipais e depois estaduais, culminou na realização da VIII Conferência Nacional de Saúde, que, realizada em 1986, congregou delegados de todo o país (LOPES, 2001, p. 27).

As teses centrais da VIII Conferência Nacional de Saúde, no sentido da universalização do atendimento à saúde, da descentralização administrativa, da participação comunitária e da redefinição paradigmática da atuação do Estado na área, visando à construção da cidadania e à garantia da saúde - para além da atenção médica - como um direito de cada brasileiro e um dever do Estado, constituídas em seu relatório final apresentado em publicação de 1987, tornaram-se poderosos instrumentos de pressão em dois eventos de grande significado, um no Executivo e outro no Legislativo (LOPES, 2001).

Em 1987, o governo implantou o SUDS Sistema Unificado e Descentralizado de Saúde, que reforçou uma tendência já prenunciada a partir do início do programa de Ações Integradas de Saúde (AIS, em 1983), a do aumento de repasses financeiros da União para estados e municípios.

Em 1988, a Constituição Brasileira referendou a nova lógica, criando o SUS - Sistema Único de Saúde - organizado segundo as diretrizes gerais apontadas pela VIII Conferência Nacional de Saúde, constituindo-se em um novo paradigma para a saúde.

Há inegáveis ganhos teóricos na conquista de um reconhecimento legal, juridicamente consagrado, do direito à saúde como um elemento de cidadania plena (LOPES, 2001).

Os princípios que regem o SUS englobam a universalidade, a eqüidade e a integralidade; $\mathrm{e}$, do ponto de vista organizacional, a descentralização, o controle social, a regionalização, a hierarquização e a complementação do setor privado (BRASIL, 1990). Com isso 
propõe-se uma nova atenção à saúde, que objetiva promoção, proteção e recuperação da saúde para todos. Dessa forma, são introduzidas na saúde pública medidas que possibilitam a prestação de serviços antes somente ofertados pelo setor privado, tanto filantrópico quanto lucrativo. São criados novos serviços e incorporados novos técnicos, passos para a discussão de um novo pressuposto que não encontre como único viés saúde enquanto ausência de doença (LOPES, 2000).

\section{PRIORIZAÇÃO DAS AÇÕES DE SAÚDE BÁSICA}

Com o avanço mundial do neoliberalismo e suas estratégias de ações para a constituição de um Estado mínimo, exatamente no momento em que toma força no Brasil a luta pela ampliação de direitos sociais, a implantação do SUS, cujas proposições estão calcadas em princípios públicos e universalizantes e não em focalizações seletivas e privatizações das políticas neoliberais, se dá sob o signo de intensa contradição entre o avanço formal jurídico institucional e as dificuldades da realidade econômica concreta.

Os princípios neoliberais, aplicados à gestão do Estado brasileiro em diferentes níveis ao longo da década de 90 levaram, dentre outros fatores, a uma implantação parcial do SUS. Conforme Campos, o Estado brasileiro "vem por ele próprio impedindo a efetiva implantação do SUS” (CAMPOS, 1997, p. 113), principalmente por meio da redução dos gastos públicos na saúde (LOPES, 2001).

Com relação à focalização das políticas, Mendes (1993) pontua:

(...) a focalização, decorre do fato de que os gastos sociais públicos chegam, em pequena proporção, aos setores pobres da sociedade e que, portanto, para eles, devem ser dirigidos, prioritariamente, os recursos para os programas sociais. Contudo, a pequena força política desses grupos populacionais, decorrentes de sua desorganização, e a pouca sensibilidade social dos neoliberais com relação a eles fazem com que a política de focalização termine por transforma-se numa neofilantropia (MENDES, 1993, p. 51).

Como exemplo de focalização, duas áreas têm se configurado como subsistemas, estando, em algumas localidades, no lugar do SUS. São elas:

- Subsistema de Atenção Básica, executado primordialmente através do Programa de Saúde da Família (PSF) e baseado na atenção simplificada;

- Subsistema de Atenção Hospitalar, centrado nas internações e procedimentos de alta complexidade.

Para a atenção básica, tópico de nosso estudo neste trabalho, tem havido um incentivo através de investimento financeiro por parte do governo federal. Estes recursos provêm da Norma Operacional Básica de 1996 (NOB/96), que atualmente prevê uma quantia adicional para o município que investir no Programa de Saúde da Família (PSF) e no Programa de Agentes Comunitários da Saúde (PACS).

Esta proposição coaduna-se com os princípios do Banco Mundial, que sugere que as ações em saúde sejam de caráter básico e fixadas para aqueles que não têm acesso ao mercado privado, ou seja, aos planos de saúde e ao desembolso direto (LOPES, 1995). Nessa direção, o Banco Mundial vem financiando a ampliação do PSF no Brasil, no que tange à sua implementação em centros urbanos mais adensados demograficamente (BRASIL, 2003).

PSF e PACS são inspirados no modelo britânico, onde a porta de entrada para o acesso ao sistema de saúde se dá de forma regular, por meio da ação do médico generalista, responsável por uma população determinada - o médico de família, além de experiências bem sucedidas no Ceará e na Paraíba em 1990, com a implantação do PACS (executado pelos agentes comunitários de saúde, supervisionados por enfermeiros). Em 1994, o Ministério da Saúde cria o Programa de Saúde da Família - PSF. Seu principal propósito: "reorganizar a prática da atenção à saúde em novas bases e substituir o modelo tradicional, levando a saúde para mais perto da família e, com isso, melhorar a qualidade de vida dos brasileiros", segundo Brasil (2003).

O Programa de Saúde da Família traduz-se como "uma estratégia que prioriza as ações de promoção, proteção e recuperação da saúde dos indivíduos e da família, do recém-nascido ao idoso, sadios ou doentes, de forma integral e contínua" (BRASIL, 2003). Essa estratégia prioriza as ações de prevenção, promoção e recuperação da saúde das pessoas, de forma integral e contínua. $\mathrm{O}$ atendimento é prestado na Unidade Básica de Saúde (UBS) ou no domicílio, pelos profissionais (médicos, enfermeiros, auxiliares de enfermagem e agentes comunitários de saúde) que compõem as Equipes de Saúde da Família (ESF). O Agente Comunitário de Saúde é uma pessoa da própria comunidade, que recebe qualificação específica, passando a fazer parte da equipe de saúde local; atende os moradores em cada casa, dando atenção a todas as questões relacionadas à saúde: identifica problemas, orienta, encaminha e acompanha a realização dos procedimentos necessários à proteção, promoção $\mathrm{e}$ recuperação/reabilitação da saúde das pessoas daquela comunidade (BRASIL, 2003). 
As proposições do Ministério da Saúde com relação ao Programa de Saúde da Família nos remetem a questões acerca dos princípios de atenção integral e universal e àquelas advindas dos programas focais.

A ampliação do atendimento por meio do trabalho do agente comunitário de saúde, o acesso ao serviço e a resolutividade dos problemas de saúde básica, bem como a organização comunitária, são argumentos que fundamentam a defesa do PSF. Contudo, a defesa da necessidade da focalização tem se baseado no barateamento de custos e nas ações de baixa complexidade tecnológica, dirigidas a grupos populacionais excluídos e muitas vezes localizados nas regiões periféricas das cidades.

Quais serão as possibilidades desta política na promoção da saúde? Afinal, o que é saúde básica?

\section{AÇÕES DE SAÚDE BÁSICA X AÇÕES BÁSICAS DE SAÚDE}

As diretrizes do SUS prevêem ações descentralizadas e territorializadas, organizadas de acordo com a demanda local. Isto significa dizer que as Unidades Básicas de Saúde (UBS) devem prover todas as intervenções sem complexidade tecnológica que dada comunidade demandar, ou seja, toda a população deve ter acesso a este serviço, inclusive portadores de deficiência física, de transtornos mentais, crianças em situação de risco, idosos, todos, enfim. A rede básica prevê um modelo que é “(...) incompatível com a idéia de que tudo que é básico é também barato, pobre e primário" (CAMPOS, 1989, p. 57). O que implica dizer que não apenas a equipe de saúde básica deve estar presente na UBS, ou seja, há a necessidade de uma incorporação de recursos humanos e estrutura física para promover ações básicas de saúde (CAMPOS, 1989).

Para o Programa de Saúde da Família são previstas ações básicas regulamentadas por uma complementaridade da NOB/96, o Manual de Organização da Atenção Básica, que discrimina tais ações, entre as quais não estão incluídas, por exemplo, a Saúde Mental, a Saúde da Pessoa Portadora de Deficiência, a Assistência Odontológica, dentre outras.

Faz-se necessário, portanto, definir ação de saúde básica e ação básica de saúde. O que aparenta ser uma simples inversão de palavras revela uma diferença de conteúdo significativa para esta discussão.

O PSF prevê ações de saúde básica, referindo-se a intervenções que digam respeito ao oferecimento de assistência para problemáticas ou doenças relacionadas aos componentes da saúde clínica, tais como: diabetes, hipertensão, pré-natal, dentre outras. Para tais ações está previsto como equipe o agente comunitário, o enfermeiro, o auxiliar de enfermagem e o médico generalista.

Já as ações básicas de saúde estão relacionadas com as demandas daquela população de acordo com suas características sócio-culturais e econômicas. Trata-se de um outro conceito de saúde, que não se restringe à ausência de doença, pois tem como desafio a integração de toda a população no território e a atenção a essa população. Aproxima-se, portanto, do conceito de Unidade Básica de Saúde, como local de promoção da saúde segundo a demanda local.

Vale ressaltar que esta discussão não tem por objetivo valorizar uma ação em detrimento da outra. Pelo contrário, nosso objetivo é ressaltar a importância de ambas, discutindo assim as políticas de financiamento e o papel igualmente relevante das ações básicas de saúde. Precisamos avançar no imaginário cultural sobre o conceito de saúde e ampliar a discussão para a promoção da saúde, da qualidade de vida e da integração social.

Não podemos fazer com que uma experiência, um modelo de atendimento transforme-se no "modelo ideal'. Segundo Campos (1997), é necessário ressaltar que fatores de risco e algumas enfermidades exigem modelos mais complexos, e as ações devem ser diferenciadas de acordo com as demandas de cada território.

Como exemplo, podemos citar a cidade de São Paulo, que apresentou, na gestão entre os anos de 1989 e 1992, a experiência de diferentes profissionais promovendo um novo conceito de saúde. Equipes com psicólogos, fisioterapeutas, fonoaudiólogos, educadores, médicos, enfermeiros e terapeutas ocupacionais, dentre outros, operacionalizaram ações básicas na prática do serviço público de saúde.

Dentre algumas experiências não tradicionais no campo da atenção à saúde básica tivemos grupo com portadores de transtorno mental grave nas UBSs, atendimento individual e em grupo para portadores de deficiência, grupos terapêuticos e de geração de renda em UBSs, ações dos Centros de Convivência e Cooperativas, além de muitos outros exemplos (BARROS et al., 1995).

\section{PROGRAMA DE SAÚDE DA FAMÍLIA - AÇÕES DE SAÚDE BÁSICA OU AÇÕES BÁSICAS DE SAÚDE?}

O PSF traz um aspecto inovador: a figura do Agente Comunitário de Saúde (ACS). Tem-se como critério a contratação de pessoas que estejam há pelo menos dois anos na comunidade e busca-se um perfil de liderança para os que exercerão tal papel.

Para Souza (2002), a atuação dos ACS está 
diretamente relacionada ao sucesso do programa:

onde as unidades e equipes de PSF funcionam, a presença dos agentes comunitários de saúde faz a diferença. (...) a disponibilidade e vontade dos Agentes Comunitários de Saúde - ACS - de aprender e ensinar, junto de sua equipe, como olhar, ouvir e entender as realidades ímpares de cada família/ comunidade, decidindo juntos formas solidárias e um outro jeito de cuidar das pessoas (p. 119).

Os ACS passam por um processo de formação em saúde para o início de seu trabalho. Eles têm a importante função de promover o acesso de todas as pessoas aos serviços de saúde, inclusive daquelas que não o fazem pelas mais diversas razões, especialmente porque não conseguem, ou porque não acreditam na resolutividade de seus problemas por esses serviços. Sendo assim, seu trabalho embute um dos princípios diretores do SUS, a universalização.

Nesta promoção do acesso de todos aos serviços de saúde são priorizadas as questões de saúde básica. Investiga-se possibilidades de doenças, auxiliase na detecção, encaminha-se para procedimentos. E esta é uma tarefa relevante do ACS uma vez que, através desta intervenção, ele ajuda a melhorar os índices de saúde da sua comunidade.

Contudo, os ACS têm a possibilidade de realizar também ações básicas de saúde.

Utilizaremos alguns exemplos de um estudo de campo que realizamos na região do Belém, na cidade de São Paulo. Esta região caracteriza-se por ser uma área empobrecida e com a presença de muitos cortiços, locais de pouca habitabilidade.

Nos seus traços gerais, o cortiço é caracterizado como habitação coletiva situada num lote de terreno onde coabita involuntariamente grande contingente humano que precisa dividir banheiros, torneiras, tanques e outras áreas de uso comum. Marcada por péssimas condições de habitabilidade quanto aos seus aspectos físicos, insalubre, sem as mínimas condições higiênicas, esta modalidade de moradia apóia-se no aluguel de cômodos de mínimas dimensões onde, em situação de flagrante promiscuidade, se espreme grande quantidade de pessoas de sexos e idades diferentes (KOWARICK; ANT, 1994, p. 86).

O Programa de Saúde da Família implantado na região do Belém pertence ao Distrito de Saúde da Mooca e iniciou suas atividades no segundo semestre de 2001. Conta atualmente com uma equipe de trabalho composta por seis agentes comunitários, um médico, uma enfermeira e duas auxiliares de enfermagem que atendem um bolsão de pobreza da região escolhido como prioritário para o início das atividades do PSF no Distrito.
Foram entrevistados os membros da equipe do PSF, bem como acompanhadas as ações de cinco agentes comunitários de saúde. Há uma particularidade nesta região, por inscrever-se em um contexto de participação ativa do movimento social organizado, especialmente do movimento popular por moradia. Três de seus agentes comunitários são membros deste movimento, sendo dois deles lideranças em suas comunidades.

Quando se perguntou aos ACS quais eram as maiores demandas locais, eles pontuaram: "as relacionadas à saúde?” e, na seqüência, enumeraram as incidências epidemiológicas de sua comunidade; em seguida, entretanto, apontaram "outras demandas" cujo auxílio para o encaminhamento também são chamados a intervir, tais como: casos de pessoas portadoras de deficiência ou transtorno mental, a questão da violência doméstica, das drogas, do cortiço, da fome, da falta de vaga em creches, etc. O ACS é visto pelo seu 'vizinho' como alguém que pode auxiliá-lo, pois está inserido em um serviço de caráter público, o que facilita a comunicação e a apresentação de suas demandas naquele momento, demandas estas que podem ou não estar relacionadas a ações básicas de saúde, mas que são, na maioria das vezes, ações sociais básicas.

As demandas que ultrapassam o âmbito da saúde básica são muitas vezes encaminhadas e não reconhecidas como trabalho da alçada do agente comunitário enquanto tal. Eles buscam informações com os profissionais da equipe, pedem apoio para esclarecimento de dadas problemáticas, perguntam sobre demais equipamentos da saúde que desconhecem e orientam a população. A maioria, no entanto, só reconhece a sua ação profissional quando se trata de encaminhamentos para demais serviços de saúde. A discussão da promoção de demais ações para além da saúde básica não está no rol daquilo que por eles é reconhecido como trabalho, fazendo-se, contudo, muitas vezes presentes na prática cotidiana.

Potencializar o trabalho dos ACS, valorizar a aproximação com a real demanda da população e, a partir daí, buscar ações intersetoriais, pode ser um caminho para a melhoria da qualidade de vida e para a ampliação das redes sociais de suporte da população.

O ACS faz parte, muitas vezes, da rede pessoal daquele que ele atende, agora profissionalmente. Por esta característica de liderança do agente, fator presente na região que estudamos, sua participação local antecede - evidentemente em outro nível de comprometimento - a sua função enquanto ACS. Ele já é conhecido, tem vínculos, entra na casa das pessoas.

Castel, sociólogo francês, compreende as redes sociais e pessoais de suporte como elementos 
fundamentais na definição de maior ou menor vulnerabilidade daquele que tem uma integração precária ao mundo do trabalho, como elementos que podem impedir o que esse autor denomina como desfiliação. Para esse autor (1994), a inserção deve ser analisada a partir de dois eixos: o da relação de trabalho (com uma gama de posições, do emprego estável à ausência completa de trabalho) e o da inserção relacional (entre a inscrição nas redes sólidas de sociabilidade e o isolamento social total). O recorte desses dois eixos circunscreve zonas diferentes do espaço social: zona de integração - onde se dispõe de garantias de um trabalho permanente e pode-se mobilizar suportes relacionais sólidos; zona de desfiliação - onde se conjuga ausência de trabalho e isolamento social, implicando uma dupla ruptura das redes de sociabilidade e participação; zona de vulnerabilidade - que associa precariedade do trabalho e fragilidade relacional (CASTEL, 1997).

O espaço comunitário destes agentes inscrevese, na maioria das vezes, em uma zona de vulnerabilidade relacional, tendo a política do PSF a possibilidade de, caso ultrapasse os limites da saúde básica, contribuir para o fortalecimento das redes sociais de suporte destas comunidades.

Os discursos do coordenador do PSF da região do Belém e da diretora do Distrito de Saúde da Mooca, local de nosso trabalho de campo, vão na direção da promoção de ações básicas de saúde para esta política. Como exemplo, apontam a implantação, atualmente em andamento, de uma equipe volante de saúde mental para as equipes atuantes na região.

Esta ação é de extrema relevância por tratarse de um bairro da região central da capital paulista que apresenta um contexto onde a violência, as drogas, a prostituição e os furtos constituem problemáticas com as quais a população se confronta cotidianamente (SPOSATI, 2001).

A ressignificação do paradigma norteador das ações do PSF, ressaltando a importância do papel do Agente Comunitário de Saúde, pode ser um importante instrumento para o fortalecimento das redes sociais de suporte da população atendida.

\section{CONSIDERAÇÕES FINAIS}

Pensar o Programa de Saúde da Família no Brasil é problematizá-lo desde o seu recorte político, dentro das proposições neoliberais, até o cotidiano das diferentes práticas que vêm se instituindo, bem como de seus limites e possibilidades.

A incongruência entre o SUS e o neoliberalismo, conforme apresentado acima, traz a discussão a respeito dos traços que demarcam o PSF e das demandas às quais vem atender, uma vez que se enquadra no âmbito da focalização das políticas sociais, porém a partir de um discurso de oferecimento de saúde integral.

A prática cotidiana, contudo, tem mostrado, na diversidade das experiências brasileiras, uma amplitude de ações plurais e que podem apresentar uma gama de oportunidades na discussão do acesso à saúde, tema relevante para o SUS.

O campo de estudo em que trabalhamos é permeado pela discussão do acesso à população e do acesso desta ao equipamento de saúde, conforme as informações trazidas pelos agentes comunitários.

A presença dos cortiços e a entrada dos ACS - principalmente daqueles ligados ao movimento de moradia - em tais espaços, têm possibilitado que a discussão do direito à assistência a saúde se dê em um lugar aonde a população raramente chega até os equipamentos devido, principalmente, ao estigma que trazem consigo por serem moradores de cortiços.

Deparamo-nos com situação igualmente delicada em uma das micro-regiões que pesquisamos, onde vivem muitos imigrantes ilegais bolivianos e que integra, em conjunto com outras quatro micro-regiões, a área de atuação do PSF do Belém. A ACS local relata que inicialmente não era nem recebida por esta população, por conta do medo que apresentavam frente à presença de uma pessoa que inicialmente era vista como 'polícia'; hoje, já conseguiu esclarecer o papel do seu trabalho e levar muitos à Unidade de Saúde. Ainda não é permitida sua entrada em muitas casas, locais onde trabalham clandestinamente, mas na porta acontecem conversas e orientações.

Um caso emblemático foi o de uma boliviana grávida, que foi convencida pela agente comunitária a fazer o pré-natal na unidade próxima à sua residência. Fez o pré-natal na UBS, o parto normal no hospital da região e recebeu um enxoval para o bebê a partir da articulação prévia da ACS junto ao serviço de assistência social do hospital. A mãe deu o nome da agente comunitária para a filha, dizendo querer homenageá-la.

Histórias de vida como essa demonstram a possibilidade de cuidados que o PSF pode promover para aqueles que não acessariam espontaneamente $o$ serviço, resultado que se torna possível a partir de sua ação no território, ampliando as possibilidades de escolha ao alcance da população local.

É importante frisar que a dimensão da atuação deve direcionar-se para a ampliação do leque de possibilidades de conhecimento da população, para que 
ela direcione os caminhos a percorrer. A depender do modo de orientação para atuação, corremos o risco de intervenções disciplinadoras que venham para determinaro 'certo'. Campos (2000) pontua tal fato como a necessidade de:

(...) investir não somente na dimensão corporal dos sujeitos conforme tradição da saúde pública (vacinas, por exemplo), mas também pensá-los como cidadãos de direitos e donos de uma capacidade crítica de reflexão e eleição mais autônoma de modos de levar a vida (p. 229).

Outro ponto a ser levantado consiste no fato de que a política de distribuição de recursos e sua priorização na saúde básica remetem à questão de que a prevenção e a promoção da saúde não esgotam o rol de ações estatais via SUS no campo da saúde pública (CAMPOS, 1997). E o próprio PSF tem sua eficiência comprometida caso não conte com uma retaguarda da rede para os encaminhamentos.

A discussão do PSF, conforme foi apresentado, traz uma gama diversificada de fatores que nele interferem e que requerem atenção, uma vez que este é um programa de investimento prioritário do Ministério da Saúde. Pensar seus limites, possibilidades, ações e resultados são desafios para a agenda da saúde no Brasil.

O que percebemos, a partir do acompanhamento das ações na região do Belém, concentrou-se na discussão das potencialidades das ações dos Agentes Comunitários de Saúde na promoção de intervenções para além das ações de saúde básica, proporcionando a tais agentes a possibilidade de atuar como elementos relevantes na reconstituição e na ressignificação das redes sociais de suporte de sua comunidade.

Resta saber se para os coordenadores e gestores do PSF, em cada nível, apoiar e reafirmar ações que desencadeiem a ampliação das redes de suporte social da comunidade configura-se como objetivo a ser atingido ou não, podendo-se, dessa forma, promover a legitimação das ações dos agentes comunitários de saúde para além da saúde básica.

MALFITANO, A. P. S.; LOPES, R. E. 'Programa de saúde da família' (family's health program) and community agent: demands for more than basic health. Rev. Ter. Ocup. Univ. São Paulo, v.14, n. 3, p. 110-7, set./dez. 2003.

\begin{abstract}
This article discusses, from a social-historical perspective of health policies in Brazil, the 'Programa de Saúde da Família' - 'PSF' (Family's Health Program). Through studies of health policies, it is observed the inclusion/exclusion of populational groups and/or problematics not usually dealt with by health services, as well as differentiated patterns of social protection, which act directly in the life of the target population. The goal of this work is to discuss the inclusion and the exclusion of those populational group's demands, as a result of the action of the 'Programa de Saúde da Família' (Family's Health Program), with a focus on the actions of communitary agents. This research took place in the district of Belém, in the city São Paulo, where the staff of 'PSF' was interviewed, and the actions of five communitary health agents were tracked. These agents work in a poor region of São Paulo's extended downtown, characterized by the presence of slums. In this region there are organized groups with high level of participation in social movements - mainly housing movements. Three communitary agents are members of these movements, and two of them are leaders in their communities. By analyzing these communitary agents' actions and their understanding of the program whose execution they are responsible for, in the communities, we discuss the actions traditionally seen as of 'basic health', as well as their relations with the so called 'health's basic actions'
\end{abstract}

KEY WORDS: Family health. Health plans and programmes. Health policy. Community networks.

\title{
REFERÊNCIAS
}

BARROS, D. D.; LOPES, R. E.; OLIVER, F. C. Novas propostas assistenciais em São Paulo: estudo da recente incorporação da terapia ocupacional, no contexto das ações de saúde mental e saúde da pessoa portadora de deficiência física, mental e/ou sensorial, no Município de São Paulo. São Paulo, 1995. (Relatório de pesquisa). 
BRASIL. Ministério da Saúde. Programa de Saúde da Família. Disponível em: <http://www.saude.gov.br/psf>. Acesso em: abr. 2003.

BRASIL. Ministério da Saúde. Secretaria Nacional de Assistência à Saúde. ABC do SUS: doutrinas e princípios. Brasília: Imprensa Oficial, 1990.

CAMPOS, G. W. S. Saúde pública e saúde coletiva: campo e núcleo de saberes e práticas. Ciên. Saúde Coletiva, ABRASCO, v. 5, n. 2, p. 219-30, 2000.

CAMPOS, G. W. S. Análise crítica das contribuições da saúde coletiva à organização das práticas de saúde no SUS. In: FLEURY, S. Saúde e democracia: a luta do CEBES. São Paulo: Lemos Editorial, 1997. p. 113-24.

CAMPOS, G. W. S. Modelos assistenciais e unidades básicas de saúde: elementos para debate. In: MERHY, E. E. (Org.) Planejamento sem normas. São Paulo: Hucitec, 1989. p. 53-60.

CASTEL, R. As dinâmicas do processo de marginalização: da vulnerabilidade à desfiliação. Cadernos CRH, Salvador, n. 26/27, p. 19-40, jan./dez., 1997.

CASTEL, R. Da indigência à exclusão, a desfiliação. Precariedade do trabalho e vulnerabilidade relacional. In: LANCETTI, A. (Org.). SaúdeLoucura, n. 4. São Paulo: Hucitec, 1994. p. 21-48.

KOWARICK, L.; ANT, C. Cem anos de promiscuidade: o cortiço na cidade de São Paulo. In: KOWARICK, L. (Org.) As lutas sociais e a cidade: São Paulo, passado e presente. $2^{\text {a }}$ ed. Rio de Janeiro: Paz e Terra, 1994. p. 73-91.

LOPES, R. E. Políticas de saúde no Brasil: construções, contradições e avanços. Rev. Ter. Ocup. Univ. São Paulo, v. 12, n. 1/3, p. 23-33, 2001.

LOPES, R. E., et al. Terapia ocupacional e políticas públicas de saúde na cidade de São Paulo. Cad. Ter. Ocup. UFSCar, São Carlos, SP, v. 8, n. 1, p. 48-56, 2000.

LOPES, R. E. Neoliberalismo e políticas públicas de saúde no Brasil. Cidadania/Textos. Cadernos EMDEC: UNICAMP, Campinas, n.6, p. 1-20, out. 1995.

MENDES, E. V. As políticas de saúde no Brasil nos anos 80: a conformação da reforma sanitária e a construção da hegemonia do projeto neoliberal. In: MENDES, E. V. (Org.) Distrito sanitário: o processo social de mudança das práticas sanitárias do Sistema Único de Saúde. São Paulo: Hucitec, 1993. p. $19-92$

MERHY, E. E. A rede básica como uma construção de saúde pública e seus dilemas. In: MERHY, E. E.; ONOCKO, R. (Org.). Agir em saúde: um desafio para o público. São Paulo: Hucitec, 1997. p. 197-228.

SOUZA, M. F. Os sinais vermelhos do PSF. São Paulo: Hucitec, 2002.

SPOSATI, A. O. Cidade em pedaços. São Paulo: Brasiliense, 2001. 